\title{
Microminerais para bovinos de corte nas pastagens nativas dos Campos de Cima da Serra, RS, Brasil ${ }^{1}$
}

\author{
Trace elements to beef cattle in the native pastures \\ of Campos de Cima da Serra, RS, Brazil
}

\author{
Carolina Wunsch ${ }^{2}$ Júlio Otávio Jardim Barcellos ${ }^{3}$ Ênio Rosa Prates ${ }^{4}$ \\ Roberto Andrade Grecellé ${ }^{5}$ Eduardo Castro da Costa ${ }^{5}$
}

\section{RESUMO}

Em face das poucas informações disponíveis sobre a composição mineral das pastagens nativas da região dos Campos de Cima da Serra (RS), o presente trabalho de pesquisa objetivou avaliar os teores dos principais microminerais, em diferentes épocas do ano, e relacionar o perfil mineral destas pastagens com as necessidades nutricionais recomendadas pelo NRC (1996) para bovinos de corte. O projeto foi conduzido em vinte propriedades particulares, em Cambará do Sul, utilizando áreas de campo nativo que estavam sendo normalmente utilizadas em pastoreio por bovinos de corte elou ovinos, e que não tinham sofrido nenhum tipo de melhoria, reforma ou recuperação (exceto queimada), no mínimo nos últimos 20 anos. Colheram-se nas diversas estações, durante um ano, e dentro de uma mesma área predeterminada em cada propriedade, amostras para determinar as concentrações de ferro, manganês, cobre e zinco. Verificou-se efeito do mês de coleta sobre todos os minerais analisados. Constataram-se teores suficientes de Mn e Fe para todas as categorias de bovinos de corte analisadas. Entretanto, algumas amostras apresentaram níveis tóxicos aos animais. Os teores de $\mathrm{Cu}$ não são suficientes para todas as categorias de bovinos em alguns meses do ano. Os teores de Zn estiveram abaixo das exigências mínimas para bovinos de corte.

Palavras-chave: bovinos de corte, minerais, pastagem nativa, exigências nutricionais, nutrição mineral.

\section{ABSTRACT}

The present study was conducted to determine the mineral status of natural range pastures of the Campos de
Cima da Serra region, State of Rio Grande do Sul, Brazil, in different months of the year, to compare them to beef cattle requirements (NRC, 1996). The project was carried out in twenty private farms, in Cambará do Sul county, on grazing areas without improvements (except burning) in the lastest twenty years. Pasture samples were collected in the several seasons during one year to determine its iron, manganese, copper and zinc levels. Effect of the season was verified on all analyzed minerals. The Mn and Fe contents on grass samples were higher than the beef cattle requirements. However, in some samples $F e$ and Mn levels were higher than the maximum tolerable for cattle. $\mathrm{Cu}$ contents were deficient in some months evaluated and $\mathrm{Zn}$ contents were lower than the required for cattle.

Key words: beef cattle, minerals, native pasture, animal requirements, mineral nutrition.

\section{INTRODUÇÃO}

A produção de bovinos de corte no Rio Grande do Sul está sustentada predominantemente na utilização de pastagens naturais. A produtividade destes animais é resultado da qualidade dessas pastagens, as quais apresentam flutuações estacionais na composição e concentração dos nutrientes disponíveis. Como resultado, os ruminantes estão freqüentemente sujeitos a deficiências nutricionais severas ou marginais de minerais (HIDIROGLOU,

${ }^{1}$ Projeto parcialmente financiado pela Bunge Fertilizantes/Serrana Nutrição Animal.

${ }^{2}$ Curso de Pós-graduação em Zootecnia, Universidade Federal do Rio Grande do Sul.

${ }^{3}$ Departemento de Zootecnia, Faculdade de Agronomia, UFRGS, CP 776, 91540-000, Porto Alegre, RS, Brasil. E-mail: julio.barcellos@ufrgs.br Autor para correspondência

${ }^{4}$ Departamento de Zootecnia, Fac. de Agronomia, UFRGS, Porto Alegre, RS, Brasil.

${ }^{5}$ Curso de Pós-graduação em Zootecnia, UFRGS, Porto Alegre, RS, Brasil. 
1979). Em geral, estas deficiências são corrigidas através de programas de suplementação mineral. Contudo, a eficácia destes programas de suplementação depende de um conhecimento prévio da real composição nutricional da dieta.

Baixa ingestão ou desbalanço dos minerais nos alimentos pode afetar negativamente a fertilidade, o ganho de peso, a produção de leite, e, em geral, a saúde dos animais. Portanto, na América Latina a atividade pecuária é freqüentemente limitada por desbalanços minerais (FICK et al., 1978). Um aporte adequado de minerais também é importante para a otimização da atividade microbiana no rúmen dos ruminantes (NRC, 1996). Assim, as deficiências produzem impactos negativos sobre o crescimento microbiano, podendo inclusive induzir uma redução da digestibilidade dos alimentos, dependendo da severidade da carência e da disponibilidade do mineral (SPEARS, 1994).

Entretanto, o excesso de alguns minerais pode dificultar a absorção ou interagir no metabolismo de outros, causando perdas na produtividade dos rebanhos e alterações reprodutivas. Dessa forma, as concentrações dos elementos essenciais devem ser mantidas dentro de limites estreitos para resguardar o funcionamento e a integridade dos tecidos, não ocorrendo prejuízos no crescimento, saúde e produtividade do animal.

Para animais em pastejo, que têm sua fonte de alimentação na pastagem nativa, sistema predominante nas principais regiões pecuárias do mundo, os desbalanços minerais que eventualmente podem aparecer têm um dos meios de verificação na análise da pastagem. Contudo, existe uma nítida influência do clima na composição mineral e nutricional das plantas, indicando a necessidade de avaliar os seus teores de minerais em diferentes estações do ano para ter de forma mais clara uma estimativa da sua composição.

No Brasil, resultados de análises de solos, plantas forrageiras e tecidos animais têm revelado ampla variedade de carências e algumas toxicidades de microminerais (TOKARNIA et al., 2000).

Os primeiros levantamentos sobre a composição mineral das pastagens nativas do RS datam dos anos 60. Posteriormente, nos anos 80, novas avaliações foram realizadas em forragens oriundas das mais diversas regiões do Estado e de uma ampla variedade de unidades de mapeamento de solos (SENGER et al., 1997; BARCELLOS et al., 2003).

Em face das poucas informações disponíveis sobre a composição mineral das forrageiras na região dos Campos de Cima da Serra, no Rio Grande do Sul, o presente trabalho de pesquisa objetivou avaliar os teores dos microelementos ferro, manganês, cobre e zinco nas pastagens naturais características desta região, em diferentes épocas do ano, e relacionar o perfil mineral destas pastagens com as necessidades nutricionais recomendadas pelo NRC (1996) para as diferentes categorias de bovinos de corte, a fim de estabelecer a necessidade ou não da suplementação dos minerais analisados.

\section{MATERIAL E MÉTODOS}

O experimento foi realizado no Município de Cambará do Sul, na região norte do Estado do Rio Grande do Sul. Foi avaliada, durante o ano de 2003, a composição dos principais microminerais da pastagem natural característica da região dos Campos de Cima da Serra. Esta região caracteriza-se pelo seu relevo acidentado, além de uma altitude elevada, com valor médio de $103 \mathrm{~m}$. As coordenadas geográficas são: $-29^{\circ}$ 03 " de latitude sul e $-50^{\circ} 09$ " de longitude oeste. O clima da região, segundo a classificação de Köppen, é temperado úmido ( $\mathrm{Cfb}$ ) com verões amenos (MORENO, 1961). A temperatura média anual é de $16,7^{\circ} \mathrm{C}$, com precipitação média anual de $1944 \mathrm{~mm}$, registrando-se maior intensidade durante a estação de inverno.

O solo das áreas estudadas é um Cambissolo Álico Húmico, de textura argilosa, com baixa saturação de bases e baixos teores de cálcio e fósforo disponível. É um solo fortemente ácido, com $\mathrm{pH}$ variando de 4,5 a 5,0 ao longo do perfil. Apresenta teores altos de matéria orgânica (em torno de $5 \%$ no horizonte superficial) e níveis tóxicos de alumínio (DNPA, 1973). A vegetação natural característica da região representa uma zona de transição entre o campo e a mata. Apresenta grande cobertura de gramíneas dos gêneros Agrostis, Andropogon, Aristida, Axonopus, Bromus, Elyonurus, Panicum, Paspalum, Piptochaetium, Poa, Schizachyrium e Trachypogon (DNPA, 1973; BURKAT, 1975). Também são encontradas muitas espécies prostradas e eretas das famílias Cyperaceae, Compositae e Leguminosae, entre outras.

Foram selecionados vinte locais de coleta, representados por propriedades rurais da região, para a obtenção das amostras de pastagem natural. Essas amostras foram coletadas em potreiros que estavam sendo normalmente utilizados em pastoreio por bovinos de corte e/ou ovinos, e que não tinham sofrido nenhum tipo de melhoria, reforma ou recuperação no mínimo nos últimos 20 anos, exceto a queimada, a

Ciência Rural, v.35, n.4, jul-ago, 2005. 
qual é geralmente utilizada no final do inverno e início da primavera (em setembro).

Com a finalidade de observar possíveis variações nas concentrações de ferro $(\mathrm{Fe})$, cobre $(\mathrm{Cu})$, manganês $(\mathrm{Mn})$ e zinco ( $\mathrm{Zn})$, foram efetuadas oito coletas durante o ano de realização do trabalho (2003), sendo duas coletas no verão, três no outono, duas no inverno e uma coleta na primavera. Em cada propriedade, e dentro de uma mesma área predeterminada, foram coletadas quatro sub-amostras da pastagem, reunidas em uma amostra única. Cada coleta foi realizada em área próxima às coletas anteriores.

O material foi cortado manualmente com tesoura inoxidável em um quadrado de $0,25 \mathrm{~m}^{2}$, rente ao solo, e acondicionado em sacos de polietileno, sem lavagem prévia. Posteriormente, o material foi pesado para determinação da disponibilidade de matéria seca (MS), seco em estufa de circulação forçada de ar, a $65^{\circ} \mathrm{C}$, por 72 horas, pesado novamente e moído em moinho tipo Willey com peneira de $1 \mathrm{~mm}$. A seguir, as amostras foram acondicionadas em sacos de polietileno e encaminhadas ao laboratório da empresa Rodes Química, em Cajati, SP, para determinação dos teores minerais e proteína bruta (PB).

As estimativas de disponibilidade de matéria seca da pastagem nativa por hectare, realizadas dentro de cada período e em cada propriedade, foram calculadas com base no teor de matéria seca a $65^{\circ} \mathrm{C}$. Os teores de PB das amostras foram calculados através do teor de $\mathrm{N}$ total da forragem, obtido pelo método Kjeldahl (AOAC, 1984). A extração dos minerais foi feita com ácido clorídrico 1:1, após calcinada toda a matéria orgânica das amostras. Os teores de $\mathrm{Fe}, \mathrm{Cu}$, $\mathrm{Mn}$ e Zn foram determinados por espectrofotometria de absorção atômica, conforme metodologias descritas em AOAC (1984).

O delineamento experimental utilizado foi o completamente casualizado. Para a interpretação estatística dos resultados, utilizou-se o modelo GLM (General Linear Model) do programa estatístico SPSS 11.5 (2002), segundo o modelo: $\mathrm{Yij}=\mathrm{M}+\mathrm{Pi}+\mathrm{Ci}+$ Eij, onde: $Y i j=$ valor observado; $\mathrm{M}=$ efeito médio; $\mathrm{Pi}=$ efeito da propriedade; $\mathrm{Ci}=$ efeito do mês de coleta; $\mathrm{Eij}=$ erro. A comparação entre médias foi efetuada pelo teste de Tukey, ao nível de significância de $5 \%$ de probabilidade.

\section{RESULTADOS E DISCUSSÃO}

Os parâmetros de qualidade avaliados mostraram que as pastagens nativas da região apresentavam uma boa disponibilidade média de matéria seca $\left(2035 \mathrm{~kg} \mathrm{ha}^{-1}\right)$ mas de baixa qualidade (em média 5,60\% de proteína bruta). Ao longo do ano, verificou-se efeito $(\mathrm{P}<0,01)$ dos meses de coleta sobre os teores médios de ferro, manganês, cobre e zinco nas pastagens.

Os teores de ferro nas pastagens estudadas variaram de 88 a 1080ppm, e são apresentados na tabela 1. Exceto pelo mês de setembro, os teores de ferro permaneceram semelhantes durante todo o ano. $\mathrm{O}$ valor mais alto de ferro observado no mês de setembro $(\mathrm{P}<0,05)$ coincide com o final do inverno, época em que a umidade do solo é bastante elevada no Rio Grande do Sul. Assim, segundo MENGEL \& KIRBY (1982), o $\mathrm{Fe}^{3+}$ é reduzido a $\mathrm{Fe}^{2+}$, que é a forma assimilável pelas plantas. No fim do inverno ou início da primavera, por ocasião do rebrote ou crescimento rápido das pastagens nativas, as concentrações de ferro podem atingir níveis muito elevados. Ainda, teores de ferro acima de 500 ppm podem ser resultado de contaminação da amostra com solo, devido a chuvas ou por ocorrência em zonas pantanosas (GAVILLON \& QUADROS, 1973).

GAVILLON \& QUADROS (1973), estudando pastagens nativas de diversos municípios do RS, encontraram teores médios de ferro um pouco inferiores aos obtidos neste trabalho, de 289ppm na primavera e 197ppm no verão. De forma semelhante, CAVALHEIRO \& TRINDADE (1992) encontraram teores médios de $235 \mathrm{ppm}$ de ferro na primavera, 167 no verão, 206 no outono e 462 ppm no inverno. Ainda, SENGER et al. (1997) observaram valores médios de 173 a 415 ppm de ferro na primavera, 171ppm no verão, 354 ppm no outono e 481 ppm no inverno, em pastagens nativas da Campanha e Depressão Central do RS.

Tabela 1 - Teores médios de ferro $(\mathrm{Fe})$ e manganês $(\mathrm{Mn})$ e a relação Fe:Mn em pastagens nativas dos Campos de Cima da Serra avaliadas em diferentes meses do ano.

\begin{tabular}{lccc}
\hline Mês de coleta & Fe $(\mathrm{ppm})$ & Mn $(\mathrm{ppm})$ & Fe:Mn \\
\hline jan & $290,7^{\mathrm{b}}$ & $465,4^{\mathrm{bc}}$ & $0,62: 1$ \\
fev & $295,4^{\mathrm{b}}$ & $435,8^{\mathrm{c}}$ & $0,68: 1$ \\
mar & $249,4^{\mathrm{b}}$ & $485,3^{\mathrm{abc}}$ & $0,51: 1$ \\
abr & $340,3^{\mathrm{b}}$ & $427,0^{\mathrm{c}}$ & $0,80: 1$ \\
mai & $387,4^{\mathrm{ab}}$ & $495,7^{\mathrm{abc}}$ & $0,78: 1$ \\
jul & $369,6^{\mathrm{ab}}$ & $578,8^{\mathrm{a}}$ & $0,64: 1$ \\
set & $531,2^{\mathrm{a}}$ & $551,3^{\mathrm{ab}}$ & $0,96: 1$ \\
dez & $265,8^{\mathrm{b}}$ & $398,6^{\mathrm{c}}$ & $0,67: 1$ \\
\hline Média & 335,86 & 479,81 & $0,71: 1$ \\
Desvio padrão & 205,57 & 142,42 & - \\
Probabilidade & 0,020 & 0,032 & - \\
\hline
\end{tabular}

a,b,c Letras diferentes na coluna diferem significativamente $(\mathrm{P}<0,05)$

Ciência Rural, v.35, n.4, jul-ago, 2005. 
Em alguns meses amostrados, foram observadas grandes variações nas concentrações de ferro nas pastagens analisadas com relação aos valores citados pela literatura. Isto pode ser devido a diferenças na composição botânica das regiões estudadas, ou ainda, a características de formação geológica próprias de cada região.

A relação $\mathrm{Fe}: \mathrm{Mn}$ observada foi sempre baixa (em média 0,71:1), variando de 0,51:1 em março, até 0,96:1 em setembro (Tabela 1). Esta relação deveria ser superior a 1, com o ferro duas ou três vezes maior que o manganês, devido à interferência deste com o ferro (GAVILLON \& QUADROS, 1973).

Os níveis de ferro encontrados nas pastagens são suficientes para atender às exigências dos bovinos de corte, estimadas pelo NRC (1996) em $50 \mathrm{ppm}$. Entretanto, os teores de ferro determinados em algumas amostras ultrapassaram a concentração máxima tolerada, estimada em 1000ppm (NRC, 1996). Ainda, pode existir a possibilidade de uma deficiência de ferro em pastagens nas quais ocorram valores baixos deste mineral (abaixo de 150ppm) junto com valores muito altos de manganês (acima de 400ppm), devido ao antagonismo entre esses minerais.

Os valores de manganês variaram de 166 a $1305 \mathrm{ppm}$ nas pastagens, sendo apresentados na tabela 1. As concentrações mais altas de manganês $(\mathrm{P}<0,05)$ foram observadas nos meses de julho e setembro (final de inverno), e as mais baixas $(\mathrm{P}<0,05)$ ocorreram de forma não linear em fevereiro, abril e dezembro, mas ambas não foram diferentes dos valores intermediários observados nos outros meses. Segundo UNDERWOOD \& SUTTLE (1999), as concentrações de manganês declinariam com a idade da planta, mas isto não foi o observado neste trabalho.

GAVILLON \& QUADROS (1973) encontraram teores médios de manganês nas pastagens do RS inferiores aos observados neste trabalho, de 366 na primavera e 367 no verão. $O$ mesmo ocorreu com CAVALHEIRO \& TRINDADE (1992), que observaram valores para o manganês de $318 \mathrm{ppm}$, $253 \mathrm{ppm}, 232 \mathrm{ppm}$ e $325 \mathrm{ppm}$, na primavera, verão, outono e inverno, respectivamente. SENGER et al. (1997), também obtiveram maiores teores de manganês nas pastagens durante o inverno do que nas outras estações do ano.

Ao compararem-se os níveis de manganês observados nas pastagens com as exigências de bovinos de corte em crescimento e terminação, estimadas em 20ppm pelo NRC (1996), e com a exigência de vacas em gestação e lactação, estimadas em 40ppm (NRC, 1996), é possível constatar-se que a pastagem é capaz de suprir adequadamente todas as categorias avaliadas. Entretanto, em 1,3\% das amostras foram obtidos teores acima de 1000 ppm de manganês, que é a concentração máxima tolerada pelos animais.

Os teores de cobre nas pastagens estudadas variaram de 1 a 78ppm. Na tabela 2 , são apresentados os teores médios deste elemento. Os maiores teores de cobre foram observados no outono, valores intermediários ocorreram no final do verão e os mais baixos foram obtidos durante o inverno, primavera e verão. De certa forma, esses resultados são contraditórios às afirmações de ADAMS \& ELPHICK (1956), de que os maiores teores de cobre ocorrem quando a planta está em período de rápido crescimento, o qual ocorreria na primavera.

GAVILLON \& QUADROS (1976) encontraram 7,1ppm de cobre na primavera e $5,7 \mathrm{ppm}$ no verão em pastagens nativas do RS. Outros trabalhos conduzidos no RS também demonstraram teores que variavam de 4 a $15 \mathrm{ppm}$ de cobre nas pastagens, sendo que as maiores variações sempre estiveram associadas à época do ano (CAVALHEIRO \& TRINDADE, 1992; SENGER et al., 1997).

Ao compararem-se os níveis médios de cobre encontrados nas pastagens com as exigências de bovinos de corte, estimadas em 10ppm pelo NRC (1996), pode-se observar que a pastagem não é capaz de suprir adequadamente os animais na primavera e início do verão. Nos outros períodos analisados, os teores encontrados nas pastagens mostram-se suficientes. Além disso, nenhuma amostra atingiu a concentração máxima tolerada pelos bovinos (100ppm). No entanto, nos meses de março, abril e maio os teores médios de cobre estão acima de 20ppm, o qual, segundo CONRAD et al. (1985), podem causar intoxicação crônica em ovinos.

Os teores de zinco nas pastagens estudadas variaram de 5 a 70ppm, e estão apresentados na tabela 2. Os teores mais baixos de zinco nas pastagens foram observados no mês de dezembro, coincidindo com o final da primavera, e os teores mais altos foram obtidos em maio (outono) e setembro (final do inverno), ambos não diferindo dos outros meses comparados. Segundo UNDERWOOD \& SUTTLE (1999), as concentrações de zinco declinam com a maturidade da planta, mas isto não foi observado neste trabalho.

CAVALHEIRO \& TRINDADE (1992) encontraram teores de zinco em pastagens de diversas unidades de mapeamento de solos do RS semelhantes ou levemente inferiores aos observados neste trabalho. SENGER et al. (1997) observaram teores de 19,5 a 22ppm de zinco na primavera, 16ppm no verão, 19,2ppm no outono e 22ppm no inverno, também em pastagens no RS, porém em outra região fisiográfica. Em

Ciência Rural, v.35, n.4, jul-ago, 2005. 
Tabela 2 - Teores médios de cobre $(\mathrm{Cu})$ e zinco $(\mathrm{Zn})$ em pastagens nativas dos Campos de Cima da Serra avaliadas em diferentes meses do ano.

\begin{tabular}{lcc}
\hline Mês de coleta & $\mathrm{Cu}(\mathrm{ppm})$ & $\mathrm{Zn}(\mathrm{ppm})$ \\
\hline jan & $2,7^{\mathrm{c}}$ & $19,3^{\mathrm{ab}}$ \\
fev & $11,2^{\mathrm{bc}}$ & $22,2^{\mathrm{ab}}$ \\
mar & $23,1^{\mathrm{ab}}$ & $20,7^{\mathrm{ab}}$ \\
abr & $24,9^{\mathrm{a}}$ & $21,4^{\mathrm{ab}}$ \\
mai & $33,1^{\mathrm{a}}$ & $23,3^{\mathrm{a}}$ \\
jul & $10,7^{\mathrm{c}}$ & $20,6^{\mathrm{ab}}$ \\
set & $6,9^{\mathrm{c}}$ & $26,2^{\mathrm{a}}$ \\
dez & $2,3^{\mathrm{c}}$ & $15,4^{\mathrm{b}}$ \\
\hline Média & 14,53 & 21,16 \\
Desvio padrão & 16,19 & 7,87 \\
Probabilidade & 0,036 & 0,038 \\
\hline
\end{tabular}

a,b,c Letras diferentes na coluna diferem significativamente $(\mathrm{P}<0,05)$.

pastagens tropicais, foram encontrados teores de $34,35 \mathrm{ppm}$ de zinco na estação seca e $23,14 \mathrm{ppm}$ na estação das águas, semelhantes aos observados neste trabalho (TEBALDI et al., 1998).

Ao compararem-se os níveis de zinco encontrados nas pastagens com as exigências de bovinos de corte, estimadas em 30ppm pelo NRC (1996), constata-se que a pastagem não é capaz de suprir adequadamente os animais, em todas as épocas do ano. Esta situação parece ser mais crítica na primavera, quando os teores médios de zinco encontrados não atingem nem a metade da quantidade necessária aos bovinos. Entretanto, apesar de baixos, os teores de zinco encontrados nas pastagens estão dentro da faixa recomendada como ideal para bovinos de corte por McDOWELL (1976), que é de 10 a 50ppm.

Em alguns casos, foram observadas grandes variações nas concentrações dos microelementos nas pastagens analisadas com relação aos valores citados pela literatura. Isto pode ser devido a diferenças na composição botânica das regiões estudadas, ou ainda, a características de formação geológica próprias de cada região.

\section{CONCLUSÕES}

As concentrações nas pastagens dos minerais estudados ( $\mathrm{Fe}, \mathrm{Mn}, \mathrm{Cu}$ e $\mathrm{Zn}$ ) variaram com o mês de coleta. As concentrações de zinco nas pastagens foram muito baixas em todos os meses estudados, não sendo suficientes para atender às exigências mínimas de produção para todas as categorias de bovinos de corte consideradas.
Os teores de ferro e manganês são suficientes para suprir às necessidades de todas as categorias de bovinos de corte, podendo inclusive alcançar níveis tóxicos aos animais. Os teores de cobre são insuficientes para atender às exigências dos bovinos de corte na primavera e início do verão.

\section{REFERÊNCIAS}

ADAMS, A.F.R.; ELPHICK, B.L. The copper content of some soils and pastures in Canterbury-Aspergillus niger method for available copper in soils. New Zealand Journal of Science and Tecnology, n.38, p.345-358, 1956.

AOAC. ASSOCIATION OFICIAL AGRICULTURAL CHEMISTS. Official Methodos of Analysis the Association of Official Analytical Chemists. 14.ed. Washington, DC, 1984. 1141p

BARCELLOS, J.O.J. et al. Suplementação mineral de bovinos de corte em ambientes subtropicais. In: BARCELLOS, J.O.J. et al. (Eds). Suplementação mineral de bovinos em regiões subtropicais. Porto Alegre: UFRGS, 2003. p.19-51.

BURKAT, A. Evolucion of grasses and grasslands in South America. Taxonomy, v.24, p.53-66, 1975.

CAVALHEIRO, A.C.L.; TRINDADE, D.S. Os minerais para bovinos e ovinos criados em pastejo. Porto Alegre: Sagra - DC Luzzatto, 1992. 142p.

CONRAD, J.H. et al. Minerais para ruminantes em pastejo em regiões tropicais. Gainesville : University of Florida, 1985. 90p. (Boletim).

DNPA. Departamento Nacional de Pesquisa Agropecuária. Divisão de Pesquisa Pedológica. Levantamento de reconhecimento dos solos do Estado do Rio Grande do Sul. Recife, 1973. 431p. (Boletim Técnico, 30).

FICK, K.R. et al. Current status of mineral research in Latin América. In: LATIN AMERICAN SYMPOSIUM ON MINERAL NUTRITION RESEARCH WITH GRAZING RUMINANTS, 1978, Gainesville. Proceedings... Gainesville : University of Flórida, 1978. p.149-162.

GAVILLON, O.; QUADROS, A.T. O ferro e o manganês em pastagens nativas do Rio Grande do Sul. Pesquisa Agropecuária Brasileira, Brasília, v.8, p.47-54, 1973.

GAVILLON, O.; QUADROS, A.T.F. O cobre, o molibdênio e o sulfato inorgânico em pastagens nativas do Rio Grande do Sul. Anuário Técnico IPZFO, v.3, p.423-453, 1976.

HIDIROGLOU, M. Trace element deficiencies and fertility in ruminants: a review. Journal of Dairy Science, v.62, p.1195-1206, 1979.

McDOWELL, L.R. Mineral deficiencies and toxicities and their effect on beef production in developing countries. In: SMITH, A.J. (Ed). Beef cattle production in developing countries. Edinburg : Centre for Tropical Veterinary Medicine of the University of Edinburg, 1976. p.216-241. 
MENGEL, K.; KIRBY, E.A. Principles of plant nutrition. Bern : International Potash Institute, 1982. 655p.

Moreno, J.A. Clima do Rio Grande do Sul. Porto Alegre: Secretaria da Agricultura, 1961. $42 \mathrm{p}$.

NRC. NATIONAL RESEARCH COUNCIL. Nutrient requirements of beef cattle. 7.ed. Washington, DC : National Academy of Sciences, 1996. 234p.

SENGER, C.G.D. et al. Teores minerais em pastagens do Rio Grande do Sul. II. Sódio, enxofre, zinco, cobre, ferro e manganês. Pesquisa Agropecuária Brasileira, v.32, n.1, p.101-108, 1997.

SPEARS, J.W. Minerals in forage. In: FAHEY JR., G.C. (Ed.) Forage quality, evaluation and utilization.
[S.1.] : American Society of Agronomy, 1994. p.281317 .

SPSS. User's guide: Statistics. SPSS. Version 11.5. Chicago. IL : Headquarters, 2002. Software.

TEBALDI, F.L.H. et al. Composição mineral de pastagens das Regiões Norte e Noroeste do Estado do Rio de Janeiro. In: REUNIÃO ANUAL DA SOCIEDADE BRASILEIRA DE ZOOTECNIA, 35., 1998, Botucatu. Anais... Botucatu : SBZ, 1998. p.337-340.

TOKARNIA, C.H. et al. Deficiências minerais em animais de fazenda, principalmente bovinos em regime de campo. Pesquisa Veterinária Brasileira, v.20, n.3, p.127-138, 2000.

UNDERWOOD, E.J.; SUTTLE, N.F. The mineral nutrition of livestock. 3.ed. New York : CABI, 1999. 601p. 